\title{
黄淮海平原南部不同种植体系周年气候资源分配与利用特征研究
}

\author{
周宝元 ${ }^{1}$ 葛均筑 ${ }^{2}$ 侯海鹏 $^{3}$ 孙雪芳 ${ }^{4}$ 丁 在松 $^{1}$ 李从锋 ${ }^{1}$ 马 玮 ${ }^{1, *}$ \\ 赵明 1 ,*
}

${ }^{1}$ 中国农业科学院作物科学研究所 / 农业部作物生理生态与栽培重点开放实验室, 北京 $100081 ;{ }^{2}$ 天津农学院农学与资源环境学院, 天 津 300384; ${ }^{3}$ 天津市农业发展服务中心种植业技术推广服务部，天津 $300061 ;{ }^{4}$ 青岛农业大学农学院，山东青岛 266109

摘 要：探明不同种植体系周年产量、气候资源分配及其利用效率特征, 建立周年气候资源优化配置的定量指标, 为 进一步提升黄淮海区域周年产量潜力和资源利用效率提供理论依据。本研究利用 $2011-2015$ 年河南新乡定位试验数 据, 定量分析了冬小麦-夏玉米、冬小麦-夏大豆、双季玉米和一季春玉米 4 个种植体系产量、生物量、干物质产能、 光温资源分配及其利用效率。结果表明, 冬小麦-夏玉米和双季玉米体系 4 年产量、生物量和干物质产能差异均不显 著, 但显著高于冬小麦-夏大豆和一季春玉米体系, 平均增幅分别为 $45.4 \% \sim 61.5 \% 、 37.3 \% \sim 71.3 \%$ 和 $35.7 \% \sim 70.7 \%$; 双 季玉米和一季春玉米体系周年辐射生产效率、籽粒及总生物量光能利用效率均显著高于冬小麦-夏玉米和冬小麦-夏 大豆体系, 其中周年辐射生产效率平均增幅为 $11.8 \% \sim 66.7 \%$, 籽粒及总生物量光能利用效率分别提高 $0.13 \sim 0.42$ 和 0.18 0.69 百分点。进一步分析周年气候资源分配特征，冬小麦-夏玉米体系两季积温分配率分别为 $45.6 \%$ 和 $54.4 \%$, 积温比值为 0.8 , 双季玉米两季积温分配率为 $51.4 \%$ 和 $48.6 \%$, 积温比值为 1.1 。综合分析产量和资源利用效率, 冬小 麦-夏玉米和双季玉米种植体系可作为黄淮海区种植模式优化布局和农业生产可持续发展的重要支撑, 而明确主要 种植体系积温分配率和积温比值等定量指标可为进一步优化周年气候资源配置, 挖掘黄淮海两熟区周年产量潜力和 资源利用效率提供重要参考。

关键词：黄淮海平原南部; 种植体系; 产量; 资源分配; 资源利用效率

\section{Characteristics of annual climate resource distribution and utilization for dif- ferent cropping systems in the south of Yellow-Huaihe-Haihe Rivers plain}

\author{
ZHOU Bao-Yuan ${ }^{1}$, GE Jun-Zhu ${ }^{2}$, HOU Hai-Peng ${ }^{3}$, SUN Xue-Fang ${ }^{4}$, DING Zai-Song ${ }^{1}$, LI Cong-Feng ${ }^{1}$, \\ MA Wei ${ }^{1, *}$, and ZHAO Ming ${ }^{1, *}$ \\ ${ }^{1}$ Institute of Crop Sciences, Chinese Academy of Agricultural Sciences / Key Laboratory of Crop Physiology and Ecology, Ministry of Agriculture, \\ Beijing 100081, China; ${ }^{2}$ College of Agronomy \& Resource and Environment, Tianjin Agricultural University, Tianjin 300384, China; ${ }^{3}$ Planting \\ Technology Extension, Department of Tianjin Agricultural Development Service Center, Tianjin 300061, China; ${ }^{4}$ College of Agronomy, Qingdao \\ Agricultural University, Qingdao 266109, Shandong, China
}

\begin{abstract}
Clarifying the characteristics of annual yield, distribution and utilization of climatic resources, and establishing rational quantitative indexes of annual climatic resources distribution for different cropping systems are helpful to provide theoretical basis for further improving annual yield and resource use efficiency in the Yellow-Huaihe-Haihe Rivers plain. In this study, the experiment was conducted from 2011 to 2015 at Xinxiang, Henan province to analyze the grain yield, biomass, dry matter production energy, and distribution and utilization efficiency of climatic resources under four cropping systems, namely winter wheat-summer maize, winter wheat-summer soybean, double maize and one-season spring maize. There were no differences in the annual grain yield, total biomass, and dry matter production energy between the winter wheat-summer maize and double maize cropping systems, but they were significantly higher than those of the winter wheat-summer soybean and one-season spring
\end{abstract}

\footnotetext{
本研究由国家重点研发计划项目(2018YFD0300504)资助。

This study was supported by the National Key Research and Development Program of China (2018YFD0300504).

*通信作者(Corresponding authors): 赵明, E-mail: zhaoming@caas.cn, Tel: 010-82108752; 马玮, E-mail: mawei02@caas.cn

第一作者联系方式: E-mail: zhoubaoyuan@caas.cn

Received (收稿日期): 2019-09-10; Accepted (接受日期): 2019-12-26; Published online (网络出版日期): 2020-01-15.

URL: http://kns.cnki.net/kcms/detail/11.1809.s.20200115.0912.002.html
} 
maize cropping systems, with an average increase of $45.4 \%-61.5 \%, 37.3 \%-71.3 \%$, and $35.77 \%-70.7 \%$, respectively. The annual radiation production efficiency, radiation use efficiency of grain and total biomass for double maize and one-season spring maize cropping systems were significantly higher than those of the winter wheat-summer maize and winter wheat-summer soybean cropping systems, with an average increase of $11.8 \%-66.7 \%$ in the annual radiation production efficiency, and $0.13-0.42$ and 0.18-0.69 percentage points increase in the radiation use efficiency of grain and total biomass, respectively. The accumulative temperature distribution rate for two seasons of winter wheat-summer maize was $45.6 \%$ and $54.4 \%$, respectively, while those of double maize was $51.4 \%$ and $48.6 \%$, respectively. The accumulative temperature ratio between two seasons was of winter wheat-summer maize 0.8 , while that of double maize was 1.1 . Considering both yield and resource use efficiency, winter wheat-summer maize and double maize cropping systems can be used to optimize the layout of planting patterns and support the sustainable development of agricultural production in the Yellow-Huaihe-Haihe Rivers plain. Furthermore, clarifying the accumulated temperature distribution rate and the accumulated temperature ratio between two seasons is helpful to optimize climate resource distribution, and further improve the yield potential and the resources use efficiency of double cropping system in the YellowHuaihe-Haihe Rivers plain.

Keywords: the south of Yellow-Huaihe-Haihe Rivers plain; cropping system; yield; resource distribution; resource use efficiency

黄淮海平原是我国重要的粮食生产基地, 种植 模式以冬小麦-夏玉米一年两熟为主, 其中小麦种 植面积和产量分别占全国 $60 \%$ 和 $50 \%$, 玉米种植面 积和产量分别占全国 36\%和 40\%左右, 对保障我国 粮食安全发挥了重要作用 ${ }^{[1]}$ 。然而, 受全球气候变化 影响, 该区极端气候频发, 导致冬小麦生长期内易 遭遇冻害、冬旱和春旱 ${ }^{[2-3]}$, 夏玉米授粉结实期常遭 遇高温、干旱或阴雨寡照等逆境 ${ }^{[4-5]}$, 减产风险加大。 同时, 持续增温、干旱及日照时数降低等现象 ${ }^{[6-7]}$, 导致传统种植模式下冬小麦-夏玉米品种、播期及生 育期等与光、温、水资源不匹配，限制了作物产量 潜力和气候资源利用效率的进一步提升 ${ }^{[8-11]}$ 。研究表 明, 作物理论最大光能利用率为 $5 \% \sim 6 \%{ }^{[12]}$, 而黄淮 平原年光能利用率低于 $2 \%{ }^{[13]}$ 。

探明黄淮海平原主要种植体系周年气候资源分 配与利用特征, 并进一步优化调控周年气候资源配 置, 是挖掘周年产量潜力和资源利用效率的重要途 径之一。冬小麦-夏玉米一年两熟种植体系中, 农民 习惯 9 月中下旬收获玉米, 10 月中旬播种小麦, 这段 时间该区光照充足、日平均气温 $17^{\circ} \mathrm{C}$ 左右, 积温量 高达 $510 \sim 550^{\circ} \mathrm{C}$, 造成大量光温资源浪费 ${ }^{[7,14]}$ 。与冬 小麦-夏玉米种植体系生育进程相似 ${ }^{[15]}$, 冬小麦-夏 大豆种植体系中大豆收获至小麦播种期间空闲期 $20 \sim 25 \mathrm{~d}$, 浪费光能 $240 \sim 260 \mathrm{MJ} \mathrm{m}^{-2}$ 、积温 $409 \sim 495^{\circ} \mathrm{C}$ 。 王树安 ${ }^{[16]}$ 在华北平原建立的冬小麦-夏玉米“双晚” 技术模式, 将冬小麦播种期由 10 月初推迟至 10 月 中旬, 夏玉米收获期由 9 月中旬推迟至 9 月底, 对两 季气候资源优化配置, 在保证小麦正常生长不减产 的情况下, 将更多的资源分配给玉米, 使其周年产 量达到 $15,000 \mathrm{~kg} \mathrm{hm}^{-2}$ 以上, 光、温资源生产力分别 提高 $64 \%$ 和 $124 \%$ 。另外, 发展多元种植模式, 也可
以最大限度地从空间和时间上提高光、热、水分等 资源利用效率。陈阜等 ${ }^{[17]}$ 和赵秉强等 ${ }^{[18]}$ 研究评价了 冬小麦/春玉米/夏玉米和冬小麦/春玉米/夏玉米/秋 玉米等集约多熟种植体系，表明这些种植体系均具 有较高的产量潜力和资源利用效率, 周年产量可突 破 $18,000 \sim 20,000 \mathrm{~kg} \mathrm{hm}^{-2}$ 。Meng 等 ${ }^{[19]}$ 研究评价了冬 小麦/夏玉米-春玉米两年三熟和一季春玉米种植模 式, 认为适当减少冬小麦种植比例, 增加高资源利 用效率和高产潜力玉米的比例, 可实现年平均节约 灌溉量达 $40 \%$, 氮肥用量减少 $59 \%$ 。双季玉米种植 体系两季不同熟期品种的配置使玉米生长发育与自 然资源的变化同步协调, 且两季的生育期处于该区 一年中光、温、水的集中期，可以充分利用气候资 源，周年光、温生产效率分别高于冬小麦-夏玉米模 式 $26.1 \%$ 和 $6 . \%^{[20-22]}$ 。可见, 优化传统两熟种植体 系周年气候资源分配，并发展其他资源高效的种植 体系作为补充, 可以最大限度地利用周年气候资 源。然而, 由于目前关于黄淮海主要种植体系周年 气候资源分配与利用的定量特征尚不明确, 尚未建 立合理的周年气候资源定量优化配置方案, 限制了 该区周年产量与资源利用效率的进一步提升及多元 化种植体系发展。为此, 本研究拟通过 4 年定位试 验分析, 探明黄淮海主要种植模式(冬小麦-夏玉米、 冬小麦-夏大豆、双季玉米和一季春玉米)产量、光 温水资源分配及其利用效率等特征, 以期为黄淮海 平原建立资源高效的种植模式及其合理的资源配置 方案提供理论依据和技术支撑。

\section{1 材料与方法}

\section{1 试验地概况}

中国农业科学院作物科学研究所河南新乡 
(37 $\left.41^{\prime} 02^{\prime \prime} \mathrm{N}, 116^{\circ} 37^{\prime} 23^{\prime \prime} \mathrm{E}\right)$ 试验基地处暖温带大陆 性季风气候区, 年平均气温 $14^{\circ} \mathrm{C}$, 全年 $\geq 10^{\circ} \mathrm{C}$ 积 温 $4647.2^{\circ} \mathrm{C}$, 年降水量 $573.4 \mathrm{~mm}$, 多在 7、8 月间, 年日照时数 $2323.9 \mathrm{~h}$, 基本能够满足冬小麦-夏玉 米、冬小麦-夏大豆和双季玉米等一年两熟模式种植。
试验田土壤类型为沙壤土, 耕层含有机质 $12.9 \mathrm{~g} \mathrm{~kg}^{-1}$ 、 速效氮 $63.8 \mathrm{mg} \mathrm{kg}^{-1}$ 、速效磷 $15.9 \mathrm{mg} \mathrm{kg}^{-1}$ 、速效 钾 $112.1 \mathrm{mg} \mathrm{kg}^{-1}, \mathrm{pH} 8.18$ 。图 1 为 2011 年 10 月 至 2015 年 11 月年新乡日均温度、辐射量及降雨 量数据。

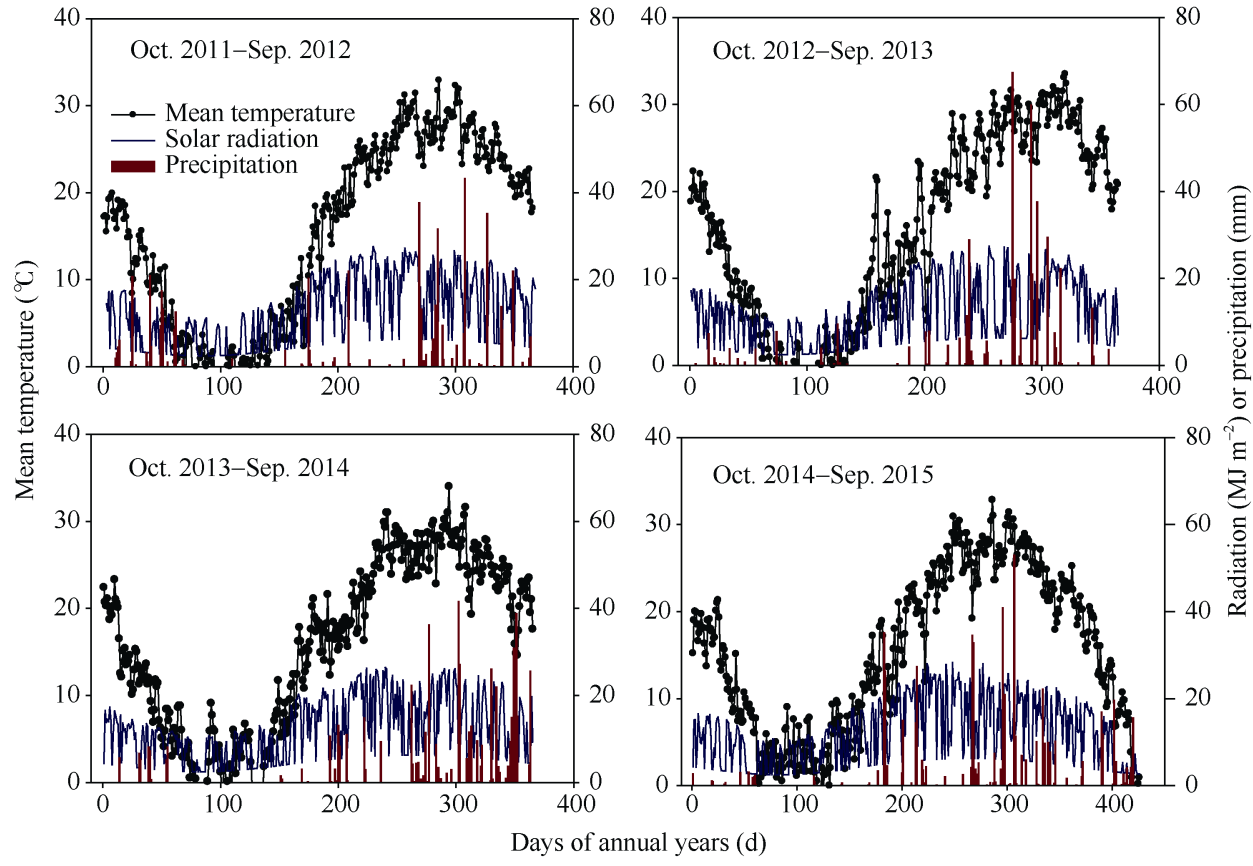

图 12011 年 10 月至 2015 年 11 月年新乡日均温度、辐射量及降雨量

Fig. 1 Daily mean temperature, radiation and precipitation at Xinxiang from Oct. 2011 to Nov. 2015

\section{2 试验设计}

2011-2015 年, 采用随机区组设计, 共设置 4 个种植模式处理, 分别为冬小麦-夏玉米 $(\mathrm{W}-\mathrm{M})$ 、冬 小麦-夏大豆 $(\mathrm{W}-\mathrm{S})$ 、双季玉米 $(\mathrm{M}-\mathrm{M})$ 和一季春玉米 $(\mathrm{M})$ 。小区面积为 $127.2 \mathrm{~m}^{2}(4.8 \mathrm{~m} \times 26.5 \mathrm{~m}), 3$ 次重 复。除播种期和收获期外, 各模式均按当前高产栽 培方式种植。具体种植方案见表 1 。选用当地主栽 的高产稳产品种为试验材料, 冬小麦和夏大豆分别 采用 $17 \mathrm{~cm}$ 和 $40 \mathrm{~cm}$ 等行距种植, 玉米采用大小行 $(40 \mathrm{~cm} \times 80 \mathrm{~cm})$ 种植。小麦播前浇足底墒水 $(75 \mathrm{~mm})$, 基施氮磷钾复合肥(15\%-15\%-15\%) $750 \mathrm{~kg} \mathrm{hm}^{-2}$, 拔 节期结合浇水(75 mm)追施尿素 $225 \mathrm{~kg} \mathrm{hm}^{-2}$; 玉米 随播种施氮磷钾复合肥 (15\%-15\%-15\%) $540 \mathrm{~kg}$ $\mathrm{hm}^{-2}$, 于拔节期结合灌水 $(75 \mathrm{~mm})$ 或降雨追施尿素 $450 \mathrm{~kg} \mathrm{hm}^{-2}$; 大豆播前浇足底墒水 $(75 \mathrm{~mm})$, 随播 种施氮磷钾复合肥(15\%-15\%-15\%) $450 \mathrm{~kg} \mathrm{hm}^{-2}$, 于 分枝期结合灌水 $(75 \mathrm{~mm})$ 或降雨追施尿素 $150 \mathrm{~kg}$ $\mathrm{hm}^{-2}$ 。双季玉米第一季播后人工覆膜。其他管理同 常规高产田。

\section{3 测定项目及方法}

1.3.1 气象资料收集 气象数据来源于国家气象 局网站(http://cdc.nmic.cn/home.do/), 主要包括平均 温度、日照时数和降雨量等指标。

1.3.2 产量测定 冬小麦收获时, 从每小区按固 定的标点取 $1 \mathrm{~m}$ 双行测定穗数, 实收 $1 \mathrm{~m}^{2}$ 测产, 并 随机抽取 20 穗考种，将小区收获籽粒自然风干，在 含水量为 $13 \%$ 时称量, 折合成公顷产量。玉米收获 时, 每小区取中间 4 行所有的果穗 $\left(60 \mathrm{~m}^{2}\right)$, 并随机 抽取 20 穗考种，收获穗全部脱粒后经自然风干，测 定籽粒含水量, 按 $14 \%$ 含水量折合成公顷产量。夏 大豆收获时，每个小区按固定的标点取 $1 \mathrm{~m}^{2}$ 测定荚 数, 并实收 $1 \mathrm{~m}^{2}$ 测产, 将小区收获籽粒自然风干, 在含水量为 $13 \%$ 时称量, 折合成公顷产量, 同时从 每个点取 20 株考种, 调查荚数、荚粒数和千粒重。

1.3.3 生物量测定于收获期, 按“对角线”法 从每小区选取小麦 20 株, 按叶、茎、鞘、穗分样; 每 个小区取玉米代表性植株 5 株, 按茎、叶、鞘、穗 粒、苞叶、穗轴器官分样; 每小区取大豆代表性 
表 $12011-2015$ 年不同种植体系种植方案

Table 1 Scheme for high-yielding cultivation of different cropping systems from 2011 to 2015

\begin{tabular}{|c|c|c|c|c|c|c|}
\hline $\begin{array}{l}\text { 年份 } \\
\text { Year }\end{array}$ & $\begin{array}{c}\text { 种植体系 } \\
\text { Cropping } \\
\text { system } \\
\end{array}$ & $\begin{array}{l}\text { 作物类型 } \\
\text { Crop type }\end{array}$ & $\begin{array}{c}\text { 品种 } \\
\text { Variety }\end{array}$ & $\begin{array}{c}\text { 密度 } \\
\text { Plant density } \\
\left(\times 10^{4} \text { plant } \mathrm{hm}^{-2}\right) \\
\end{array}$ & $\begin{array}{c}\text { 播种期 } \\
\text { Sowing date } \\
\text { (month/day) }\end{array}$ & $\begin{array}{c}\text { 收获期 } \\
\text { Harvest date } \\
\text { (month/day) }\end{array}$ \\
\hline \multirow[t]{7}{*}{$2011-2012$} & $\mathrm{~W}-\mathrm{M}$ & 冬小麦 Winter wheat & 矮抗 58 Aikang 58 & 375 & $10 / 13$ & $6 / 5$ \\
\hline & & 夏玉米 Summer maize & 郑单 958 Zhengdan 958 & 7.50 & $6 / 12$ & $9 / 28$ \\
\hline & $\mathrm{W}-\mathrm{S}$ & 冬小麦 Winter wheat & 矮抗 58 Aikang 58 & 375 & $10 / 13$ & $6 / 5$ \\
\hline & & 夏大豆 Summer soybean & 中黄 35 Zhonghuang 35 & 22.5 & $6 / 13$ & $9 / 25$ \\
\hline & $\mathrm{M}-\mathrm{M}$ & 早春季 Spring maize & 先玉 335 Xianyu 335 & 6.75 & $3 / 21$ & $7 / 20$ \\
\hline & & 晚夏季 Summer maize & 郑单 958 Zhengdan 958 & 7.50 & $7 / 20$ & $11 / 11$ \\
\hline & M & 春玉米 Spring maize & 先玉 335 Xianyu 335 & 6.00 & $4 / 22$ & $9 / 3$ \\
\hline \multirow[t]{7}{*}{$2012-2013$} & $\mathrm{~W}-\mathrm{M}$ & 冬小麦 Winter wheat & 矮抗 58 Aikang 58 & 450 & $10 / 10$ & $6 / 4$ \\
\hline & & 夏玉米 Summer maize & 郑单 958 Zhengdan 958 & 7.50 & $6 / 8$ & $9 / 25$ \\
\hline & $\mathrm{W}-\mathrm{S}$ & 冬小麦 Winter wheat & 矮抗 58 Aikang 58 & 450 & $10 / 10$ & $6 / 2$ \\
\hline & & 夏大豆 Summer soybean & 中黄 35 Zhonghuang 35 & 30.0 & $6 / 10$ & $9 / 25$ \\
\hline & $\mathrm{M}-\mathrm{M}$ & 早春季 Spring maize & 先玉 335 Xianyu 335 & 6.75 & $3 / 23$ & $7 / 19$ \\
\hline & & 晚夏季 Summer maize & 郑单 958 Zhengdan 958 & 7.50 & $7 / 21$ & $11 / 15$ \\
\hline & M & 春玉米 Spring maize & 先玉 335 Xianyu 335 & 6.00 & $4 / 25$ & $9 / 4$ \\
\hline \multirow[t]{7}{*}{$2013-2014$} & $\mathrm{~W}-\mathrm{M}$ & 冬小麦 Winter wheat & 矮抗 58 Aikang 58 & 450 & $10 / 10$ & $5 / 29$ \\
\hline & & 夏玉米 Summer maize & 郑单 958 Zhengdan 958 & 7.50 & $6 / 8$ & $9 / 27$ \\
\hline & $\mathrm{W}-\mathrm{S}$ & 冬小麦 Winter wheat & 矮抗 58 Aikang 58 & 450 & $10 / 10$ & $6 / 2$ \\
\hline & & 夏大豆 Summer soybean & 中黄 35 Zhonghuang 35 & 30.0 & $6 / 8$ & $9 / 22$ \\
\hline & $\mathrm{M}-\mathrm{M}$ & 早春季 Spring maize & 先玉 335 Xianyu 335 & 6.75 & $3 / 25$ & $7 / 18$ \\
\hline & & 晚夏季 Summer maize & 郑单 958 Zhengdan 958 & 7.50 & $7 / 19$ & $11 / 12$ \\
\hline & M & 春玉米 Spring maize & 先玉 335 Xianyu 335 & 6.00 & $4 / 27$ & $9 / 8$ \\
\hline \multirow[t]{7}{*}{ 2014-2015 } & $\mathrm{W}-\mathrm{M}$ & 冬小麦 Winter wheat & 矮抗 58 Aikang 58 & 450 & $10 / 9$ & $6 / 5$ \\
\hline & & 夏玉米 Summer maize & 郑单 958 Zhengdan 958 & 7.50 & $6 / 13$ & $9 / 25$ \\
\hline & $\mathrm{W}-\mathrm{S}$ & 冬小麦 Winter wheat & 矮抗 58 Aikang 58 & 450 & $10 / 9$ & $6 / 8$ \\
\hline & & 夏大豆 Summer soybean & 中黄 35 Zhonghuang 35 & 30.0 & $6 / 15$ & $9 / 25$ \\
\hline & $\mathrm{M}-\mathrm{M}$ & 早春季 Spring maize & 先玉 335 Xianyu 335 & 6.75 & $3 / 23$ & $7 / 21$ \\
\hline & & 晚夏季 Summer maize & 郑单 958 Zhengdan 958 & 7.50 & $7 / 22$ & $11 / 21$ \\
\hline & M & 春玉米 Spring maize & 先玉 335 Xianyu 335 & 6.00 & $4 / 28$ & $9 / 10$ \\
\hline
\end{tabular}

W-M: 冬小麦-夏玉米一年两熟; W-S: 冬小麦-夏大豆一年两熟; M-M: 双季玉米一年两熟; M: 一季春玉米。

W-M: winter wheat-summer maize double cropping system; W-S: winter wheat-summer soybean double cropping system; M-M: double maize cropping system; M: spring maize.

植株 10 株, 按叶、茎、荚等器官分样, 置烘箱 $105^{\circ} \mathrm{C}$ 杀青 $30 \mathrm{~min}, 80^{\circ} \mathrm{C}$ 烘至恒重, 计算群体地上 部干物重。

1.3.4 干物质产能 参考王美云等 ${ }^{[22]}$ 计算方法, 干物质产能以单位面积生产的干物质产量的干重热 值表示。干物质产能 $\left(\mathrm{MJ} \mathrm{m}^{-2}\right)=$ 单位面积的干物质 产量 $\times$ 干重热值

干重热值 $(\mathrm{GCV})$ 指每克干物质完全燃烧所释放
的能量 $\left(\mathrm{J} \mathrm{g}^{-1}\right)^{[23]}$, 本试验玉米植株干重热值为 $1.807 \times 10^{4} \mathrm{~J} \mathrm{~g}^{-1}$, 小麦植株干重热值为 $1.747 \times 10^{4} \mathrm{~J} \mathrm{~g}^{-1}$, 大豆种子干重热值为 $2.145 \times 10^{4} \mathrm{~J} \mathrm{~g}^{-1}$, 大豆秸秆干重 热值为 $1.655 \times 10^{4} \mathrm{~J} \mathrm{~g}^{-1}$ 。

1.3.5 光、温资源分配率与分配比值参照以下 公式计算资源分配率和资源分配比值等指标 ${ }^{[24]}$ 。

积温分配率 $(\mathrm{TDR})=$ 季节内积温 $(\mathrm{Tx}) /$ 周年积温 总量 $(\mathrm{T})$ 
辐射分配率 $(\mathrm{RDR})=$ 季节内辐射量 $(\mathrm{Rx}) /$ 周年辐 射总量 $(R)$

积温比值 $(\mathrm{TR})=$ 第一季积温 $(\mathrm{T} 1) /$ 第二季积温

辐射比值 $(R R)=$ 第一季辐射量 $(R 1) /$ 第二季辐 射量(R2)

太阳总辐射 $Q=Q_{0}\left(a+b S / S_{0}\right)$

式中, $Q$ 为太阳总辐射, $Q_{0}$ 为天文辐射, $S$ 为太阳实测 日照时数, $\mathrm{S}_{0}$ 为太阳可照时数, $S / S_{0}$ 为日照百分率, $a$ 、 $b$ 为待定系数 ${ }^{[25]}$ 。

积温计算中, 小麦下限温度取值为 $0^{\circ} \mathrm{C}$, 玉米和 大豆下限温度取值为 $10^{\circ} \mathrm{C}^{[26]}$ 。

1.3.6 光、温生产效率 光能生产效率 $\left(\mathrm{g} \mathrm{MJ}^{-1}\right)=$ 单位面积籽粒产量/生育期间太阳辐射总量; 积温生 产效率 $\left(\mathrm{kg} \mathrm{hm}^{-2}{ }^{\circ} \mathrm{C}^{-1}\right)=$ 单位面积籽粒产量/生育期 间积温总量; 降水生产效率 $\left(\mathrm{kg} \mathrm{hm}^{-2} \mathrm{~mm}^{-1}\right)=$ 单位 面积籽粒产量/生育期间降水总量。

\subsection{7 光能利用效率}

光能利用效率 RUE $(\%)=(W \times H) / \sum Q \times 100 \%$

式中, $H$ 为每克干物质燃烧时释放出的热量; $W$ 是测 定期间干物质的增加量(即净生产量); $\sum Q$ 是同期的 总光照辐射量。

\section{4 数据分析}

利用Microsoft Excel 2003 进行数据初步整理, 利用SPSS16.0软件进行方差分析和多重比较, 采用 SigmaPlot 10.0软件作图。

\section{2 结果与分析}

\section{1 不同种植体系周年及单季产量}

由图 2 可以看出, 年际间各种植体系周年及单 季产量变化趋势基本一致。4 个种植体系中, 冬小麦 -夏玉米 $(\mathrm{W}-\mathrm{M})$ 和双季玉米种植体系 $(\mathrm{M}-\mathrm{M})$ 周年产 量最高, 4 年平均周年产量分别为 $19,748.5 \mathrm{~kg} \mathrm{hm}^{-2}$ 和 $19,332.4 \mathrm{~kg} \mathrm{hm}^{-2}$, 二者之间无显著差异, 但显著 高于冬小麦-夏大豆 $(\mathrm{W}-\mathrm{S})$ 和一季春玉米体系 $(\mathrm{M})$, 增幅分别为 $48.6 \%$ 和 $45.4 \%, 61.5 \%$ 和 $58.1 \%$; 冬小麦 一夏大豆体系周年产量显著高于一季春玉米体系。对 于一年两熟体系来说, 双季玉米体系第一季作物(玉 米)产量最高, 4 年平均产量为 $10,225.8 \mathrm{~kg} \mathrm{hm}^{-2}$, 显 著高于冬小麦-夏玉米和冬小麦-夏大豆体系第一季 (小麦), 增幅分别为 $12.6 \%$ 和 $10.9 \%$ ，但二者之间差 异不显著; 冬小麦-夏玉米体系第二季作物(玉米)产 量最高, 4 年平均产量为 $10,639.8 \mathrm{~kg} \mathrm{hm}^{-2}$, 显著高于 双季玉米和冬小麦-夏大豆体系第二季, 增幅分别
为 $17.2 \%$ 和 $162.9 \%$; 冬小麦-夏大豆体系第一季小麦 产量与冬小麦-夏玉米第一季小麦产量差异不显著, 但第二季大豆产量显著低于冬小麦-夏玉米和双季 玉米体系第二季作物产量。
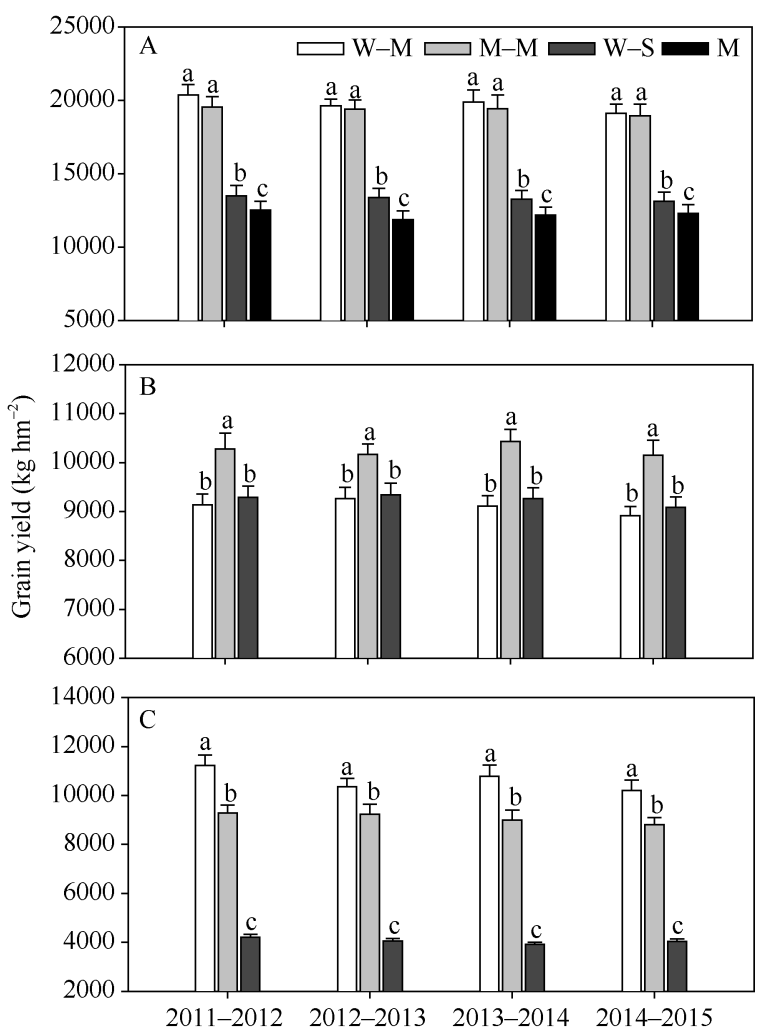

图 2 2011-2015 年不同种植体系单季及周年产量

Fig. 2 Grain yield of different cropping systems from 2011 to 2015

$\mathrm{A}$ 为周年产量; $\mathrm{B}$ 为一年两熟体系第一季产量; $\mathrm{C}$ 为一年两熟体系 第二季产量; $\mathrm{W}-\mathrm{M}$ : 冬小麦-夏玉米一年两熟; M-M: 双季玉米 一年两熟; W-S: 冬小麦-夏大豆一年两熟; M: 一季春玉米。图 柱上不同小写字母表示在 0.05 水平差异显著。

A: the annual grain yield; B: the grain yield of first season; C: the grain yield of second season; $\mathrm{W}-\mathrm{M}$ : winter wheat-summer maize double cropping system; M-M: double maize cropping system; $\mathrm{W}-\mathrm{S}$ : winter wheat-summer soybean double cropping system; M: spring maize. Bars superscripted by different lowercases are significantly different at the 0.05 probability level.

\section{2 不同种植体系生物量及干物质产能}

由图 3-A C 可以看出, 年际间各种植体系生物 量变化趋势基本一致。4 个种植体系中, 冬小麦-夏 玉米和双季玉米体系周年生物量最高, 4 年均值分别 为 $39,649.3 \mathrm{~kg} \mathrm{hm}^{-2}$ 和 $39,513.9 \mathrm{~kg} \mathrm{hm}^{-2}$, 二者差异不 显著, 但显著高于冬小麦-夏大豆和一季春玉米体 系, 4 年平均增幅分别为 $37.8 \%$ 和 $37.3 \%, 71.3 \%$ 和 $70.7 \%$; 冬小麦-夏大豆体系周年生物量显著高于一 季春玉米体系。对于一年两熟体系来说，双季玉米 体系第一季作物生物量最高, 4 年平均生物量为 
$20,634.0 \mathrm{~kg} \mathrm{hm}^{-2}$, 分别高于冬小麦-夏玉米和冬小麦夏大豆体系 $8.1 \%$ 和 $9.3 \%$ ，但二者之间差异不显著; 冬小麦-夏玉米体系第二季作物生物量最高, 4 年平 均生物量为 $20,441.6 \mathrm{~kg} \mathrm{hm}^{-2}$, 分别高于双季玉米和 冬小麦-夏大豆体系 $8.1 \%$ 和 $106.4 \%$; 冬小麦-夏大亘 体系第一季小麦生物量与冬小麦-夏玉米体系第一 季小麦差异不显著, 但第二季大豆生物量显著低于 冬小麦-夏玉米和双季玉米体系第二季玉米。

各种植体系干物质产能与生物量趋势一致 (图 3-D F)。4 个种植体系中, 冬小麦-夏玉米和双季 玉米体系周年干物质产能均最高, 4 年均值分别为 70.9 $\mathrm{MJ} \mathrm{m}^{-2}$ 和 $71.4 \mathrm{MJ} \mathrm{m}^{-2}$, 二者差异不显著, 但显著高于
冬小麦-夏大豆和一季春玉米体系, 4 年平均增幅分别 为 $35.7 \%$ 和 $36.5 \%, 69.7 \%$ 和 $70.7 \%$; 冬小麦-夏大豆体 系周年干物质产能显著高于一季春玉米体系。对于一 年两熟体系来说, 双季玉米体系第一季作物干物质产 能最高, 4 年平均值为 $37.2 \mathrm{MJ} \mathrm{m}^{-2}$, 分别高于冬小麦夏玉米和冬小麦-夏大豆体系 $10.4 \%$ 和 $11.5 \%$ ，但二者 之间差异不显著; 冬小麦-夏玉米体系第二季作物干 物质产能最高, 4 年平均为 $37.3 \mathrm{MJ} \mathrm{m}^{-2}$, 分别高于双季 玉米和冬小麦-夏大豆体系 $8.6 \%$ 和 $104.2 \%$; 冬小麦夏大豆体系第一季小麦干物质产能与冬小麦-夏玉米体 系第一季小麦差异不显著, 但第二季大豆干物质产能 显著低于冬小麦-夏玉米和双季玉米体系第二季玉米。
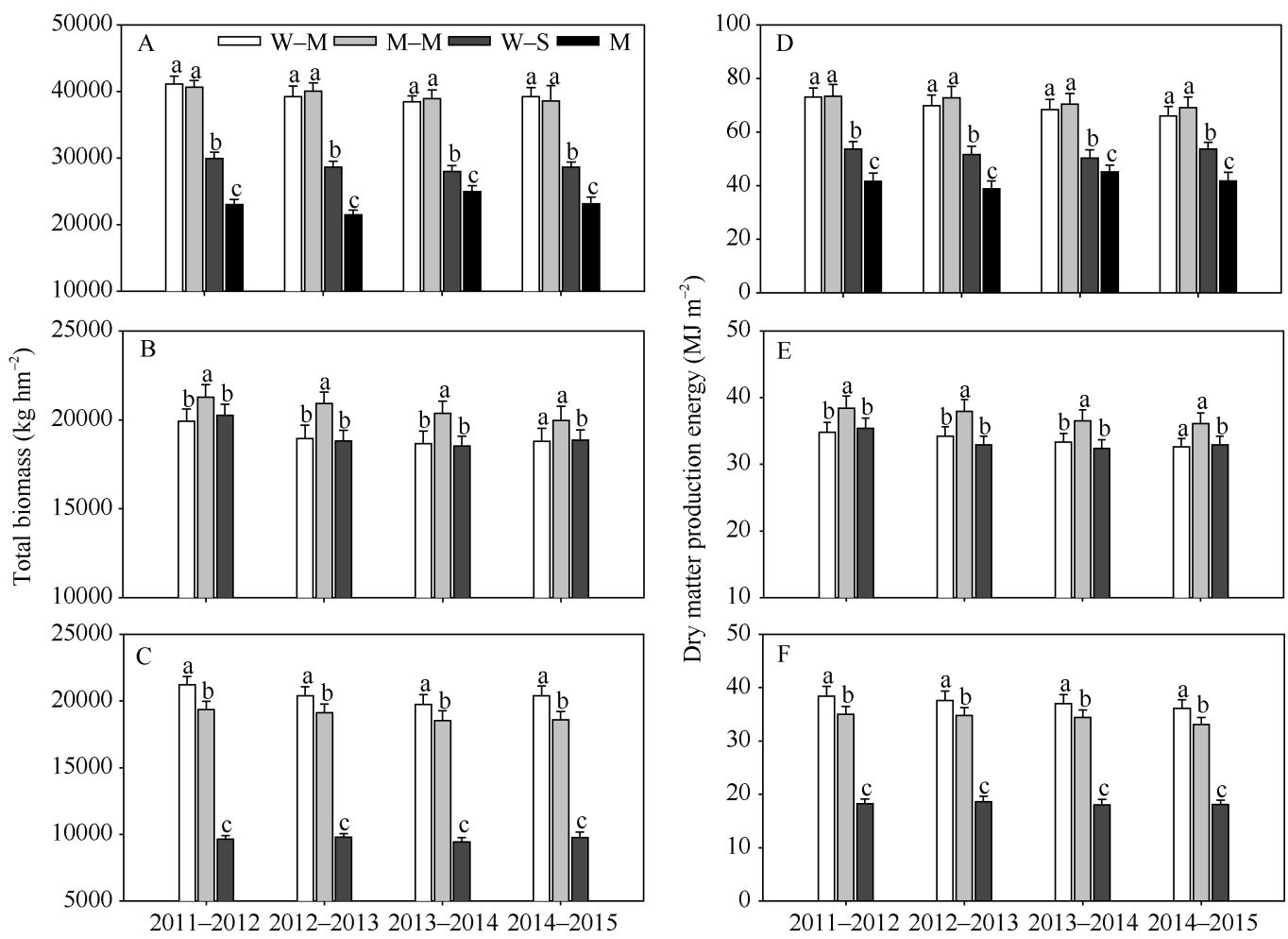

图 $32011-2015$ 年不同种植体系周年生物量及干物质产能

Fig. 3 Total biomass, and dry matter production energy of different cropping systems from 2011 to 2015

$\mathrm{A}$ 为周年生物量; $\mathrm{B}$ 为一年两熟体系第一季生物量; $\mathrm{C}$ 为一年两熟体系第二季生物量; $\mathrm{D}$ 为周年干物质产能; $\mathrm{E}$ 为一年两熟体系第一季干 物质产能; $\mathrm{F}$ : 为一年两熟体系第二季干物质产能; $\mathrm{W}-\mathrm{M}$ : 冬小麦-夏玉米一年两熟; $\mathrm{M}-\mathrm{M}$ : 双季玉米一年两熟; W-S: 冬小麦-夏大豆 一年两熟; M: 一季春玉米。图柱上不同小写字母表示在 0.05 水平差异显著。

A: the annual total biomass; B: the biomass of first season; C: the biomass of the second season; D: the annual dry matter production energy; E: the dry matter production energy of first season; F: the dry matter production energy of second season; W-M: winter wheat-summer maize double cropping system; M-M: double maize cropping system; W-S: winter wheat-summer soybean double cropping system; M: spring maize. Bars superscripted by different lowercases are significantly different at the 0.05 probability level.

\section{3 不同种植体系周年光温资源分配}

由表 2 可以看出, 年际间各种植体系积温和辐射 分配变化趋势基本一致。对 4 个种植体系积温分配 4 年平均值分析发现, 双季玉米体系第一季积温量最高, 4 年平均值为 $2611.3^{\circ} \mathrm{C}$, 占周年积温总量的 $51.4 \%$, 显
著高于冬小麦-夏玉米和冬小麦-夏大豆体系第一季积 温量, 4 年平均增幅分别为 $11.1 \%$ 和 $10.3 \%$; 冬小麦-夏 玉米和冬小麦-夏大豆体系第二季积温量最高, 4 年平 均值分别为 $2801.7^{\circ} \mathrm{C}$ 和 $2684.9^{\circ} \mathrm{C}$, 分别占周年积温量 的 $54.4 \%$ 和 $53.1 \%$ ，二者差异不显著，但显著高于双季 
表 2 2011-2015 年不同种植体系季节间积温分配

Table 2 Distribution of accumulated temperature of different cropping systems from 2011 to 2015

\begin{tabular}{|c|c|c|c|c|c|c|c|}
\hline \multirow{2}{*}{$\begin{array}{l}\text { 年份 } \\
\text { Year }\end{array}$} & \multirow{2}{*}{$\begin{array}{c}\text { 处理 } \\
\text { Treatment }\end{array}$} & \multicolumn{2}{|c|}{ 第一季 First season } & \multicolumn{2}{|c|}{ 第二季 Second season } & \multicolumn{2}{|c|}{ 周年 Annual } \\
\hline & & $\begin{array}{c}\text { 积温 } \\
\text { AT }\left({ }^{\circ} \mathrm{C}\right) \\
\end{array}$ & $\begin{array}{c}\text { 分配率 } \\
\text { TDR (\%) }\end{array}$ & $\begin{array}{c}\text { 积温 } \\
\text { AT }\left({ }^{\circ} \mathrm{C}\right) \\
\end{array}$ & $\begin{array}{c}\text { 分配率 } \\
\text { TDR (\%) }\end{array}$ & $\begin{array}{c}\text { 积温 } \\
\text { AT }\left({ }^{\circ} \mathrm{C}\right) \\
\end{array}$ & $\begin{array}{c}\text { 两季比 } \\
\text { TR }\end{array}$ \\
\hline \multirow[t]{4}{*}{$2011-2012$} & $\mathrm{~W}-\mathrm{M}$ & 2348.5 & 45.4 & 2828.7 & 54.6 & 5177.2 & 0.83 \\
\hline & $\mathrm{M}-\mathrm{M}$ & 2681.1 & 52.3 & 2442.4 & 47.7 & 5123.5 & 1.10 \\
\hline & $\mathrm{W}-\mathrm{S}$ & 2348.5 & 46.6 & 2692.0 & 53.4 & 5040.5 & 0.87 \\
\hline & M & - & - & - & - & 3275.0 & - \\
\hline \multirow[t]{4}{*}{$2012-2013$} & $\mathrm{~W}-\mathrm{M}$ & 2255.0 & 43.7 & 2908.2 & 56.3 & 5163.2 & 0.78 \\
\hline & $\mathrm{M}-\mathrm{M}$ & 2562.0 & 50.0 & 2558.8 & 50.0 & 5120.8 & 1.00 \\
\hline & $\mathrm{W}-\mathrm{S}$ & 2296.0 & 46.1 & 2687.5 & 53.9 & 4983.5 & 0.85 \\
\hline & M & - & - & - & - & 3334.5 & - \\
\hline \multirow[t]{4}{*}{ 2013-2014 } & W-M & 2267.3 & 45.3 & 2736.5 & 54.7 & 5003.8 & 0.83 \\
\hline & $\mathrm{M}-\mathrm{M}$ & 2631.7 & 52.2 & 2406.5 & 47.8 & 5038.2 & 1.09 \\
\hline & $\mathrm{W}-\mathrm{S}$ & 2358.6 & 47.1 & 2644.2 & 52.9 & 5002.8 & 0.89 \\
\hline & M & - & - & - & - & 3324.6 & - \\
\hline \multirow[t]{4}{*}{ 2014-2015 } & $\mathrm{W}-\mathrm{M}$ & 2527.4 & 48.0 & 2733.4 & 52.0 & 5260.8 & 0.92 \\
\hline & $\mathrm{M}-\mathrm{M}$ & 2570.3 & 51.1 & 2460.4 & 48.9 & 5030.7 & 1.04 \\
\hline & W-S & 2467.7 & 47.6 & 2716.0 & 52.4 & 5183.7 & 0.91 \\
\hline & M & - & - & - & - & 3261.9 & - \\
\hline \multirow[t]{4}{*}{ 平均值 Mean } & $\mathrm{W}-\mathrm{M}$ & $2349.6 \mathrm{~b}$ & $45.6 \mathrm{~b}$ & $2801.7 \mathrm{a}$ & $54.4 \mathrm{a}$ & $5151.3 \mathrm{a}$ & $0.8 \mathrm{c}$ \\
\hline & $\mathrm{M}-\mathrm{M}$ & $2611.3 \mathrm{a}$ & $51.4 \mathrm{a}$ & $2467.0 \mathrm{~b}$ & $48.6 \mathrm{~b}$ & $5078.3 \mathrm{a}$ & $1.1 \mathrm{a}$ \\
\hline & $\mathrm{W}-\mathrm{S}$ & $2367.7 \mathrm{~b}$ & $46.9 \mathrm{~b}$ & $2684.9 \mathrm{a}$ & $53.1 \mathrm{a}$ & $5052.6 \mathrm{a}$ & $0.9 \mathrm{~b}$ \\
\hline & M & - & - & - & - & $3299.0 \mathrm{~b}$ & - \\
\hline
\end{tabular}

W-M: 冬小麦-夏玉米一年两熟; M-M：双季玉米一年两熟; W-S: 冬小麦-夏大豆一年两熟; M: 一季春玉米。AT: 积温量; TDR: 积温 分配率; TR: 两季积温比值。标以不同小写字母的平均值在 0.05 水平差异显著。

W-M: winter wheat-summer maize double cropping system; M-M: double maize cropping system; W-S: winter wheat-summer soybean double cropping system; M: spring maize. AT: accumulated temperature; TDR: accumulated temperature distribution rate; TR: accumulated temperature ratio of two seasons. Means within a column followed by different letters are significantly different at the 0.05 probability level.

玉米体系第二季积温量, 4 年平均增幅分别为 $13.6 \%$ 和 $8.8 \%$ 。3 个一年两熟种植体系周年积温总量差异不显 著, 但显著高于一季春玉米体系, 两季间积温比值 4 年平均分别为 $1.1 、 0.9$ 和 0.8 , 差异显著。

比较各体系光照资源分配特征发现(表 3), 4 个 种植体系中, 冬小麦-夏玉米和冬小麦-夏大豆体系 第一季分配辐射量最高, 4 年平均值分别为 2156.7 $\mathrm{MJ} \mathrm{m}{ }^{-2}$ 和 $2169.5 \mathrm{MJ} \mathrm{m}^{-2}$, 分别占周年总辐射量的 $57.0 \%$ 和 $58.2 \%$ ，二者差异不显著，但显著高于双季 玉米体系第一季辐射量, 4 年平均增幅分别为 $12.5 \%$ 和 $13.1 \%$; 冬小麦-夏玉米体系第二季辐射量最高, 4 年平均值为 $1630.2 \mathrm{MJ} \mathrm{m}^{-2}$, 占全年辐射总量的 $43.0 \%$, 与冬小麦-夏大豆体系第二季辐射量差异不 显著, 但显著高于双季玉米体系第二季辐射量, 4 年 平均增幅为 $7.4 \%$ 。对于周年辐射量来说, 冬小麦夏玉米和冬小麦-夏大豆体系周年辐射量最高, 4 年 平均值分别为 $3787.0 \mathrm{MJ} \mathrm{m}^{-2}$ 和 $3727.3 \mathrm{MJ} \mathrm{m}^{-2}$, 显著
高于双季玉米和一季春玉米体系周年辐射量, 4 年平 均增幅分别为 $10.2 \%$ 和 $8.5 \%, 84.3 \%$ 和 $81.4 \%$; 两季 间辐射量比值无显著差异。

\section{4 不同种植体系光温资源利用效率}

由表 4 可以看出, 年际间各种植体系积温和光能 生产效率变化趋势基本一致。4 个种植体系中, 双季玉 米体系第一季玉米的积温生产效率最高, 4 年平均值为 $4.1 \mathrm{~kg} \mathrm{hm}^{-2}{ }^{\circ} \mathrm{C}^{-1}$, 显著高于冬小麦-夏玉米和冬小麦夏大豆体系的小麦季，4 年平均增幅分别为 $7.9 \%$ 和 $10.8 \%$; 冬小麦-夏玉米和双季玉米体系的第二季玉米 积温生产效率 4 年平均值分别为 $3.9 \mathrm{~kg} \mathrm{hm}^{-2}{ }^{\circ} \mathrm{C}^{-1}$ 和 $3.8 \mathrm{~kg} \mathrm{hm}^{-2}{ }^{\circ} \mathrm{C}^{-1}$, 二者差异不显著, 但显著高于冬小 麦-夏大豆体系的夏大豆季, 4 年平均增幅分别为 $129.4 \%$ 和 $123.5 \%$; 双季玉米体系周年积温生产效率最 高, 4 年平均值为 $4.0 \mathrm{~kg} \mathrm{hm}^{-2}{ }^{\circ} \mathrm{C}^{-1}$, 与冬小麦一夏玉米 和一季春玉米体系周年温度生产效率差异不显著, 但 显著高于冬小麦-夏大豆体系, 4 年平均增幅为 $53.8 \%$ 。 
表 $32011-2015$ 年不同种植体系季节间辐射分配

Table 3 Distribution of accumulated radiation of different cropping systems from 2011 to 2015

\begin{tabular}{|c|c|c|c|c|c|c|c|}
\hline \multirow{2}{*}{$\begin{array}{l}\text { 年份 } \\
\text { Year }\end{array}$} & \multirow{2}{*}{$\begin{array}{c}\text { 处理 } \\
\text { Treatment }\end{array}$} & \multicolumn{2}{|c|}{ 第一季 First season } & \multicolumn{2}{|c|}{ 第二季 Second season } & \multicolumn{2}{|c|}{ 周年 Annual } \\
\hline & & $\begin{array}{c}\text { 辐射量 } \\
\mathrm{Ra}\left(\mathrm{MJ} \mathrm{m}^{-2}\right)\end{array}$ & $\begin{array}{c}\text { 分配率 } \\
\text { RDR (\%) }\end{array}$ & $\begin{array}{c}\text { 辐射量 } \\
\mathrm{Ra}\left(\mathrm{MJ} \mathrm{m}^{-2}\right)\end{array}$ & $\begin{array}{c}\text { 分配率 } \\
\text { RDR (\%) }\end{array}$ & $\begin{array}{c}\text { 辐射量 } \\
\mathrm{Ra}\left(\mathrm{MJ} \mathrm{m}^{-2}\right)\end{array}$ & $\begin{array}{c}\text { 两季比 } \\
\text { RR }\end{array}$ \\
\hline \multirow[t]{4}{*}{ 2011-2012 } & W-M & 2184.2 & 55.7 & 1738.2 & 44.3 & 3922.4 & 1.3 \\
\hline & $\mathrm{M}-\mathrm{M}$ & 2062.2 & 56.8 & 1570.7 & 43.2 & 3632.9 & 1.3 \\
\hline & $\mathrm{W}-\mathrm{S}$ & 2184.2 & 57.5 & 1614.0 & 42.5 & 3798.1 & 1.4 \\
\hline & M & - & - & - & - & 2110.2 & - \\
\hline \multirow[t]{4}{*}{$2012-2013$} & $\mathrm{~W}-\mathrm{M}$ & 2131.2 & 56.5 & 1638.1 & 43.5 & 3769.2 & 1.3 \\
\hline & $\mathrm{M}-\mathrm{M}$ & 1761.0 & 52.6 & 1585.2 & 47.4 & 3346.2 & 1.1 \\
\hline & $\mathrm{W}-\mathrm{S}$ & 2160.5 & 58.9 & 1510.3 & 41.1 & 3670.9 & 1.4 \\
\hline & M & - & - & - & - & 1995.6 & - \\
\hline \multirow[t]{4}{*}{ 2013-2014 } & $\mathrm{W}-\mathrm{M}$ & 2103.4 & 58.5 & 1493.2 & 41.5 & 3596.6 & 1.4 \\
\hline & $\mathrm{M}-\mathrm{M}$ & 1873.4 & 58.7 & 1316.3 & 41.3 & 3189.7 & 1.4 \\
\hline & $\mathrm{W}-\mathrm{S}$ & 2173.5 & 59.8 & 1462.3 & 40.2 & 3635.8 & 1.5 \\
\hline & M & - & - & - & - & 1982.4 & - \\
\hline \multirow[t]{4}{*}{ 2014-2015 } & W-M & 2208.2 & 57.2 & 1651.4 & 42.8 & 3859.6 & 1.3 \\
\hline & $\mathrm{M}-\mathrm{M}$ & 1974.3 & 55.2 & 1600.8 & 44.8 & 3575.1 & 1.2 \\
\hline & W-S & 2159.6 & 56.8 & 1644.8 & 43.2 & 3804.4 & 1.3 \\
\hline & M & - & - & - & - & 2128.9 & - \\
\hline \multirow[t]{4}{*}{ 平均值 Mean } & $\mathrm{W}-\mathrm{M}$ & $2156.7 \mathrm{a}$ & $57.0 \mathrm{a}$ & $1630.2 \mathrm{a}$ & $43.0 \mathrm{a}$ & $3787.0 \mathrm{a}$ & $1.3 \mathrm{a}$ \\
\hline & $\mathrm{M}-\mathrm{M}$ & $1917.7 \mathrm{~b}$ & $55.8 \mathrm{~b}$ & $1518.3 \mathrm{~b}$ & $44.2 \mathrm{a}$ & $3436.0 \mathrm{~b}$ & $1.3 \mathrm{a}$ \\
\hline & $\mathrm{W}-\mathrm{S}$ & $2169.5 \mathrm{a}$ & $58.2 \mathrm{a}$ & $1557.8 \mathrm{ab}$ & $41.8 \mathrm{~b}$ & $3727.3 \mathrm{a}$ & $1.4 \mathrm{a}$ \\
\hline & M & - & - & - & - & $2054.3 \mathrm{c}$ & - \\
\hline
\end{tabular}

W-M: 冬小麦-夏玉米一年两熟; M-M: 双季玉米一年两熟; W-S: 冬小麦-夏大豆一年两熟; M: 一季春玉米。Ra: 辐射量; RDR: 辐射 分配率; RR: 两季辐射量比值。标以不同小写字母的平均值在 0.05 水平差异显著。

W-M: winter wheat-summer maize double cropping system; M-M: double maize cropping system; W-S: winter wheat-summer soybean double cropping system; M: spring maize. Ra: radiation; RDR: radiation distribution rate; RR: radiation ratio of two seasons. Means within a column followed by different letters are significantly different at the 0.05 probability level.

双季玉米体系第一季玉米光能生产效率最高, 4 年平均值为 $0.54 \mathrm{~g} \mathrm{MJ}^{-1}$ ，显著高于冬小麦-夏玉米和 冬小麦-夏大豆体系第一季小麦, 4 年平均增幅分别 为 $28.6 \%$ 和 $35.0 \%$; 冬小麦-夏玉米和双季玉米体系 第二季玉米光能生产效率差异不显著, 4 年平均值分 别为 $0.64 \mathrm{~g} \mathrm{MJ}^{-1}$ 和 $0.61 \mathrm{~g} \mathrm{MJ}^{-1}$, 显著高于冬小麦-夏 大豆体系夏大豆季, 4 年平均增幅分别为 $113.3 \%$ 和 $103.3 \%$; 双季玉米和一季春玉米周年光能生产效率 差异不显著, 4 年平均值分别为 $0.57 \mathrm{~g} \mathrm{MJ}^{-1}$ 和 $0.60 \mathrm{~g}$ $\mathrm{MJ}^{-1}$, 显著高于冬小麦-夏玉米和冬小麦-夏大豆体 系周年光能生产效率， 4 年平均增幅分别为 $11.8 \%$ 和 $17.6 \%, 58.3 \%$ 和 $66.7 \%$, 冬小麦-夏大豆体系周年光 能生产效率最低。
冬小麦-夏玉米和冬小麦-夏大豆体系小麦季降 水生产效率 4 年平均值分别为 $65.5 \mathrm{~kg} \mathrm{hm}^{-2} \mathrm{~mm}^{-1}$ 和 $63.8 \mathrm{~kg} \mathrm{hm}^{-2} \mathrm{~mm}^{-1}$, 二者差异不明显, 但显著高于 双季玉米模式第一季玉米, 4 年平均增幅分别为 $29.2 \%$ 和 $25.8 \%$; 双季玉米体系第二季玉米季降水 生产效率 4 年平均值为 $38.1 \mathrm{~kg} \mathrm{hm}^{-2} \mathrm{~mm}^{-1}$, 显著高 于冬小麦-夏玉米和冬小麦-夏大豆体系第二季, 4 年平均增幅分别为 $26.2 \%$ 和 $180.1 \%$; 双季玉米体 系周年降水生产效率 4 年平均值为 $43.8 \mathrm{~kg} \mathrm{hm}^{-2}$ $\mathrm{mm}^{-1}$ ，显著高于冬小麦-夏玉米、冬小麦-夏大豆 和一季春玉米体系，4 年平均增幅分别为 $9.0 \%$ 、 $55.9 \%$ 和 $13.5 \%$ ，冬小麦-夏大豆体系周年降水生 产效率最低。 
表 4 2011-2015 年不同种植体系积温、光能和降水生产效率

Table 4 Production efficiency of accumulated temperature, radiation, and precipitation of different cropping systems from 2011 to 2015

\begin{tabular}{|c|c|c|c|c|c|c|c|c|c|c|}
\hline \multirow{2}{*}{$\begin{array}{l}\text { 年份 } \\
\text { Year }\end{array}$} & \multirow{2}{*}{$\begin{array}{l}\text { 处理 } \\
\text { Treat- } \\
\text { ment }\end{array}$} & \multicolumn{3}{|c|}{$\begin{array}{c}\text { 积温生产效率 } \\
\text { Production efficiency of AT } \\
\left(\mathrm{kg} \mathrm{hm}^{-2} \mathrm{C}^{-1}\right) \\
\end{array}$} & \multicolumn{3}{|c|}{$\begin{array}{c}\text { 光能生产效率 } \\
\text { Production efficiency of Ra } \\
\left(\mathrm{g} \mathrm{MJ}^{-1}\right)\end{array}$} & \multicolumn{3}{|c|}{$\begin{array}{c}\text { 降水生产效率 } \\
\text { Production efficiency of } \mathrm{Pr} \\
\left(\mathrm{kg} \mathrm{hm}^{-2} \mathrm{~mm}^{-1}\right) \\
\end{array}$} \\
\hline & & $\begin{array}{c}\text { 第一 } \\
\text { 季 } \\
\text { First } \\
\text { season }\end{array}$ & $\begin{array}{l}\text { 第二季 } \\
\text { Second } \\
\text { season }\end{array}$ & $\begin{array}{c}\text { 周年 } \\
\text { Annual }\end{array}$ & $\begin{array}{l}\text { 第一季 } \\
\text { First } \\
\text { season }\end{array}$ & $\begin{array}{l}\text { 第二季 } \\
\text { Second } \\
\text { season }\end{array}$ & $\begin{array}{c}\text { 周年 } \\
\text { Annual }\end{array}$ & $\begin{array}{l}\text { 第一季 } \\
\text { First } \\
\text { season }\end{array}$ & $\begin{array}{l}\text { 第二季 } \\
\text { Second } \\
\text { season }\end{array}$ & $\begin{array}{c}\text { 周年 } \\
\text { Annual }\end{array}$ \\
\hline \multirow[t]{4}{*}{ 2011-2012 } & $\mathrm{W}-\mathrm{M}$ & 3.8 & 4.0 & 3.9 & 0.42 & 0.65 & 0.52 & 48.5 & 41.4 & 44.3 \\
\hline & $\mathrm{M}-\mathrm{M}$ & 4.0 & 3.8 & 3.9 & 0.50 & 0.58 & 0.54 & 68.5 & 56.1 & 62.0 \\
\hline & $\mathrm{W}-\mathrm{S}$ & 3.8 & 1.7 & 2.7 & 0.41 & 0.29 & 0.36 & 47.7 & 17.3 & 29.8 \\
\hline & M & - & - & 3.8 & - & - & 0.59 & - & - & 51.5 \\
\hline \multirow[t]{4}{*}{ 2012-2013 } & $\mathrm{W}-\mathrm{M}$ & 3.8 & 3.9 & 3.9 & 0.42 & 0.62 & 0.51 & 88.4 & 32.2 & 45.9 \\
\hline & $\mathrm{M}-\mathrm{M}$ & 4.1 & 3.8 & 4.0 & 0.58 & 0.60 & 0.59 & 35.3 & 61.5 & 44.4 \\
\hline & W-S & 3.8 & 1.8 & 2.7 & 0.40 & 0.33 & 0.37 & 85.1 & 15.8 & 32.9 \\
\hline & M & - & - & 3.6 & - & - & 0.60 & - & - & 31.2 \\
\hline \multirow[t]{4}{*}{ 2013-2014 } & $\mathrm{W}-\mathrm{M}$ & 3.7 & 4.0 & 3.9 & 0.42 & 0.67 & 0.52 & 69.7 & 22.5 & 32.9 \\
\hline & $\mathrm{M}-\mathrm{M}$ & 4.0 & 3.8 & 3.9 & 0.56 & 0.69 & 0.61 & 60.4 & 25.7 & 37.0 \\
\hline & W-S & 3.7 & 1.8 & 2.7 & 0.40 & 0.33 & 0.37 & 68.5 & 11.5 & 24.8 \\
\hline & M & - & - & 3.9 & - & - & 0.65 & - & - & 37.7 \\
\hline \multirow[t]{4}{*}{ 2014-2015 } & $\mathrm{W}-\mathrm{M}$ & 3.5 & 3.9 & 3.8 & 0.40 & 0.62 & 0.50 & 55.5 & 32.2 & 40.0 \\
\hline & $\mathrm{M}-\mathrm{M}$ & 4.1 & 3.8 & 4.0 & 0.52 & 0.58 & 0.55 & 42.6 & 35.6 & 39.0 \\
\hline & W-S & 3.5 & 1.4 & 2.4 & 0.40 & 0.24 & 0.33 & 53.5 & 12.3 & 26.1 \\
\hline & M & - & - & 3.8 & - & - & 0.58 & - & - & 38.7 \\
\hline \multirow{4}{*}{$\begin{array}{c}\text { 平均值 } \\
\text { Mean }\end{array}$} & $\mathrm{W}-\mathrm{M}$ & $3.8 \mathrm{~b}$ & $3.9 \mathrm{a}$ & $3.9 \mathrm{a}$ & $0.42 \mathrm{~b}$ & $0.64 \mathrm{a}$ & $0.51 \mathrm{~b}$ & $65.5 \mathrm{a}$ & $30.2 \mathrm{~b}$ & $40.2 \mathrm{~b}$ \\
\hline & $\mathrm{M}-\mathrm{M}$ & $4.1 \mathrm{a}$ & $3.8 \mathrm{a}$ & $4.0 \mathrm{a}$ & $0.54 \mathrm{a}$ & $0.61 \mathrm{a}$ & $0.57 \mathrm{a}$ & $50.7 \mathrm{~b}$ & $38.1 \mathrm{a}$ & $43.8 \mathrm{a}$ \\
\hline & $\mathrm{W}-\mathrm{S}$ & $3.7 \mathrm{~b}$ & $1.7 \mathrm{~b}$ & $2.6 \mathrm{~b}$ & $0.40 \mathrm{~b}$ & $0.30 \mathrm{~b}$ & $0.36 \mathrm{c}$ & $63.8 \mathrm{a}$ & $13.6 \mathrm{c}$ & $28.1 \mathrm{c}$ \\
\hline & M & - & - & $3.8 \mathrm{a}$ & - & - & $0.60 \mathrm{a}$ & - & - & $38.6 \mathrm{~b}$ \\
\hline
\end{tabular}

W-M: 冬小麦-夏玉米一年两熟; M-M: 双季玉米一年两熟; W-S: 冬小麦-夏大豆一年两熟; M: 一季春玉米。AT: 积温量; Ra: 辐射量; Pr: 降水量。标以不同小写字母的平均值在 0.05 水平差异显著。

W-M: winter wheat-summer maize double cropping system; M-M: double maize cropping system; W-S: winter wheat-summer soybean double cropping system; M: spring maize. AT: accumulated temperature; Ra: radiation; Pr: precipitation. Means within a column followed by different letters are significantly different at the 0.05 probability level.

由表 5 可以看出, 年际间各种植体系籽粒和总 生物量光能利用效率变化趋势基本一致。4 个种植 体系中, 双季玉米体系第一季玉米的籽粒光能利用 效率 4 年平均值为 $0.97 \%$ ，显著高于冬小麦-夏玉米 和冬小麦-夏大豆体系的小麦季; 冬小麦-夏玉米和 双季玉米第二季籽粒光能利用效率 4 年平均值分别 为 $1.15 \%$ 和 $1.10 \%$, 二者差异不显著, 但显著高于冬 小麦-夏大豆体系的夏大豆季; 双季玉米和一季春 玉米体系周年籽粒光能利用效率 4 年平均值分别为 $1.04 \%$ 和 $1.09 \%$ ，二者差异不显著，但显著高于冬小 麦-夏玉米和冬小麦-夏大豆体系。
总生物量光能利用效率变化趋势与籽粒光能利 用效率一致，4 个种植体系中，双季玉米体系第一季 玉米的总生物量光能利用效率 4 年平均值为 $1.92 \%$, 显著高于冬小麦-夏玉米和冬小麦-夏大豆体系的小 麦季; 冬小麦-夏玉米和双季玉米体系第二季总生 物量光能利用效率 4 年平均值分别为 $2.21 \%$ 和 $2.28 \%$, 二者差异不显著, 但显著高于冬小麦-夏大豆体系 的夏大豆季; 双季玉米和一季春玉米体系周年总生 物量光能利用效率 4 年平均值分别为 $2.08 \%$ 和 $2.04 \%$, 二者差异不显著, 但显著高于冬小麦-夏玉米和冬 小麦-夏大豆体系。 
表 5 2011-2015 年不同种植体系光能利用效率

Table 5 Radiation use efficiency of different cropping systems from 2011 to 2015

\begin{tabular}{|c|c|c|c|c|c|c|c|}
\hline \multirow{2}{*}{$\begin{array}{l}\text { 年份 } \\
\text { Year }\end{array}$} & \multirow{2}{*}{$\begin{array}{c}\text { 处理 } \\
\text { Treatment }\end{array}$} & \multicolumn{3}{|c|}{$\begin{array}{c}\text { 籽粒光能利用效率 } \\
\text { Radiation use efficiency of grain (\%) }\end{array}$} & \multicolumn{3}{|c|}{$\begin{array}{c}\text { 总生物量光能利用效率 } \\
\text { Radiation use efficiency of total biomass (\%) }\end{array}$} \\
\hline & & $\begin{array}{c}\text { 第一季 } \\
\text { First season }\end{array}$ & $\begin{array}{c}\text { 第二季 } \\
\text { Second season }\end{array}$ & $\begin{array}{c}\text { 周年 } \\
\text { Annual }\end{array}$ & $\begin{array}{c}\text { 第一季 } \\
\text { First season }\end{array}$ & $\begin{array}{c}\text { 第二季 } \\
\text { Second season }\end{array}$ & $\begin{array}{c}\text { 周年 } \\
\text { Annual }\end{array}$ \\
\hline \multirow[t]{4}{*}{ 2011-2012 } & $\mathrm{W}-\mathrm{M}$ & 0.73 & 1.17 & 0.92 & 1.59 & 2.21 & 1.86 \\
\hline & $\mathrm{M}-\mathrm{M}$ & 0.91 & 1.06 & 0.97 & 1.86 & 2.23 & 2.02 \\
\hline & W-S & 0.72 & 0.62 & 0.68 & 1.62 & 1.13 & 1.41 \\
\hline & M & - & - & 1.07 & - & - & 1.97 \\
\hline \multirow[t]{4}{*}{$2012-2013$} & $\mathrm{~W}-\mathrm{M}$ & 0.74 & 1.12 & 0.90 & 1.60 & 2.17 & 1.85 \\
\hline & $\mathrm{M}-\mathrm{M}$ & 1.04 & 1.09 & 1.06 & 2.10 & 2.26 & 2.17 \\
\hline & W-S & 0.70 & 0.70 & 0.70 & 1.52 & 1.23 & 1.40 \\
\hline & M & - & - & 1.08 & - & - & 1.94 \\
\hline \multirow[t]{4}{*}{ 2013-2014 } & $\mathrm{W}-\mathrm{M}$ & 0.73 & 1.22 & 0.93 & 1.58 & 2.34 & 1.90 \\
\hline & $\mathrm{M}-\mathrm{M}$ & 1.01 & 1.25 & 1.11 & 1.92 & 2.62 & 2.21 \\
\hline & $\mathrm{W}-\mathrm{S}$ & 0.72 & 0.71 & 0.70 & 1.49 & 1.23 & 1.38 \\
\hline & M & - & - & 1.17 & - & - & 2.28 \\
\hline \multirow[t]{4}{*}{ 2014-2015 } & W-M & 0.71 & 1.12 & 0.88 & 1.61 & 2.12 & 1.83 \\
\hline & $\mathrm{M}-\mathrm{M}$ & 0.95 & 1.04 & 0.99 & 1.83 & 2.07 & 1.93 \\
\hline & $\mathrm{W}-\mathrm{S}$ & 0.72 & 0.51 & 0.62 & 1.53 & 1.10 & 1.34 \\
\hline & M & - & - & 1.05 & & & 1.96 \\
\hline 平均值 & $\mathrm{W}-\mathrm{M}$ & $0.73 \mathrm{~b}$ & $1.15 \mathrm{a}$ & $0.91 \mathrm{~b}$ & $1.60 \mathrm{~b}$ & $2.21 \mathrm{a}$ & $1.86 \mathrm{~b}$ \\
\hline \multirow[t]{3}{*}{ Mean } & $\mathrm{M}-\mathrm{M}$ & $0.97 \mathrm{a}$ & $1.10 \mathrm{a}$ & $1.04 \mathrm{a}$ & $1.92 \mathrm{a}$ & $2.28 \mathrm{a}$ & $2.08 \mathrm{a}$ \\
\hline & $\mathrm{W}-\mathrm{S}$ & $0.70 \mathrm{~b}$ & $0.63 \mathrm{~b}$ & $0.67 \mathrm{c}$ & $1.54 \mathrm{~b}$ & $1.17 \mathrm{~b}$ & $1.39 \mathrm{c}$ \\
\hline & M & - & - & $1.09 \mathrm{a}$ & - & - & $2.04 \mathrm{a}$ \\
\hline
\end{tabular}

$\mathrm{W}-\mathrm{M}$ : 冬小麦-夏玉米一年两熟; M-M: 双季玉米一年两熟; W-S: 冬小麦-夏大豆一年两熟; M: 一季春玉米。标以不同小写字母的各 省平均产量在 0.05 水平差异显著。

W-M: winter wheat-summer maize double cropping system; M-M: double maize cropping system; W-S: winter wheat-summer soybean double cropping system; M: spring maize. Values followed by different letters are significantly different in grain yield among the provinces at the 0.05 probability level.

\section{3 讨论}

黄淮海地区是我国粮食主产区之一, 近年来受 气候变化和生产条件变化影响, 种植模式单一, 两 熟制季节间气候资源配置不合理，作物品种、播期、 密度、生育期等与光、温、水资源不匹配等问题突 出，限制了周年产量潜力和气候资源生产效率进一 步提升 ${ }^{[8-11]}$ 。明确黄淮海主要种植体系周年气候资源 分配与利用的定量特征, 可为进一步优化季节间资 源配置, 发展多元化高产与资源高效种植体系, 以 提高该区周年产量潜力与资源利用效率提供理论依 据。为此, 本研究通过 4 年定位试验系统分析了黄 淮海区当前主要种植体系冬小麦-夏玉米、冬小麦夏大豆、一季春玉米及双季玉米种植体系产量及资 源分配与利用定量特征, 以期为该区传统种植体系
资源优化配置和资源高效种植体系建立提供定量化 依据。研究表明, 4 个种植体系中, 由于双季玉米体 系第一季玉米产量和生物量显著高于小麦, 而冬小 麦-夏玉米体系第二季玉米产量和生物量显著高于 夏大豆和双季玉米体系的第二季玉米, 因此, 冬小 麦-夏玉米和双季玉米体系周年产量和生物量差异 不显著, 但均显著高于冬小麦-夏大豆和一季春玉 米体系。由于热值是评价植物太阳能累计和化学能 转化效率的重要指标, 可以消除作物类型差异的影 响, 为此我们比较了 4 个种植体系干物质产能的差 异。本研究中干物质产能变化趋势与产量和生物量 变化趋势基本一致, 4 个种植体系及不同作物之间 干物质产能也存在较大差异。这主要是因为 $\mathrm{C}_{4}$ 作 物玉米具有高光合效率和高物质生产能力, 而小麦 是 $\mathrm{C}_{3}$ 作物, 大豆是光呼吸作物, 二者光合能力和光 


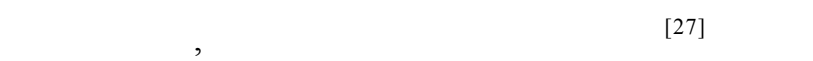
研究已证明, 适当减少冬小麦种植面积, 增加高光 合能力和高物质生产能力作物的比例, 如冬小麦/ 春玉米/夏玉米、冬小麦/春玉米/夏玉米/秋玉米、冬 小麦-夏玉米“双晚”及双季玉米等模式，均在不同 程度上增加了玉米的种植比例, 从而显著提高了周 年产量 ${ }^{[16-20]}$ 。

不同种植体系资源利用效率差异较大。本研究 中, 双季玉米体系第一季积温生产效率较高, 但由 于河南新乡双季玉米第二季生育前期温度较高, 植 株干物质积累过快, 而生育后期温度较低, 干物质 运转与分配滞后导致其产量和光温生产效率较低 ${ }^{[20-21]}$, 因此周年积温生产效率与冬小麦-夏玉米和一季春 玉米体系差异不显著, 但周年辐射生产效率显著高 于冬小麦-夏玉米体系, 与一季春玉米体系差异不 显著。另外, 由于河南新乡小麦季降水量小, 灌溉水 是小麦水分需求的主要来源 ${ }^{[28-29]}$, 因此双季玉米第 一季水分生产效率显著低于冬小麦-夏玉米和冬小 麦-夏大豆体系小麦季, 但双季玉米第二季水分生 产效率显著提高, 因此周年水分生产效率显著高于 其他种植体系。这与前人研究结果基本一致, 吴丹 等 ${ }^{[30]}$ 认为河北平原双季玉米比冬小麦-夏玉米周年 温度生产效率提高 $6.9 \% \sim 8.2 \%$, 光能生产效率增加 $9.7 \% \sim 29.0 \%$, 年总辐射利用率增加 $12.7 \%$ 29.0\%, 水分利用效率提高 $53.7 \% \sim 76.6 \%$ 。同时, 由于玉米具 有较高的产量潜力和光合效率, 双季玉米和一季春 玉米体系周年籽粒光能利用效率和总生物量光能利 用效率均显著高于其他种植体系, 但二者之间差异 不显著。可见, 适当增加高光合能力和高物质生产 能力作物的比例, 充分发挥 $\mathrm{C}_{4}$ 玉米高资源利用效率 优势, 也可有效提高多熟区周年气候资源利用效 率 ${ }^{[19-20,31]}$ 。双季玉米作为一种新型种植体系同时具

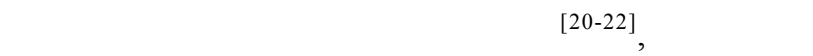
米体系具有较高的资源生产效率, 但产量较低, 且 一季种植生长期较短, 造成大量资源浪费 ${ }^{[19]}$, 冬小 麦-夏玉米作为一种传统种植体系具有较高的产量 潜力, 但资源生产效率较低, 然而冬小麦作为口粮 对保障我国粮食安全具有无可替代的作用。综合考 虑产量和资源利用效率, 冬小麦-夏玉米和双季玉 米种植体系可作为黄淮海区种植模式优化布局和农 业生产可持续发展的重要支撑, 但二者周年产量潜 力和资源利用效率还有待进一步挖掘。虽然冬小麦 一夏大豆种植体系周年产量和资源利用效率均较低,
但是由于黄淮海地区特殊的生态条件, 大豆蛋白质 含量相对较高, 在各产区具有明显的市场竞争优势, 该区大豆种植面积和产量均占全国的 $35 \%$ 左右, 在 我国大豆生产中占有非常重要的地位 ${ }^{[15,27]}$, 因此维 持或适当增加黄淮海平原冬小麦-夏大豆一年两熟种 植比例, 对于保障我国大豆安全供给具有重要作用。

作物产量形成与其所在地区的光温水等生态条 件密切相关 ${ }^{[32-35]}$, 通过季节间资源优化配置将更多 光温水等资源分配给更加高效的作物生长季是进一 步提升周年产量和资源利用效率的重要措施 ${ }^{[31,36]}$, 明确不同种植体系周年气候资源定量分配特征可为 建立合理的周年气候资源优化配置方案提供定量依 据 ${ }^{[37]}$ 。前期研究中提出了两熟制季节间资源分配率 (DR)和分配比值(R)等定量指标，可用来对不同种植 体系周年气候资源分配特征进行定量分析 ${ }^{[24]}$ 。本研 究中 3 个两熟种植体系周年积温总量差异不显著, 但 分配到两季作物的积温量、单季积温分配率及两季 积温比值差异较大, 其中双季玉米体系周年积温基 本均等分配，两季积温分配率(TDR)分别为 $51.4 \%$ 和 $48.6 \%$, 积温比值 $(\mathrm{TR})$ 为 1.1 , 而冬小麦-夏玉米和冬 小麦-夏大豆体系周年积温更多分配给第二季，两 季积温分配率分别为 $45.6 \%$ 和 $54.4 \%, 46.9 \%$ 和 $53.1 \%$, 积温比值分别为 0.8 和 0.9 。与积温不同, 双季玉米体 系周年辐射总量显著低于冬小麦-夏玉米和冬小麦夏大豆体系, 但三者周年辐射分配率均表现为第一 季较大, 且两季间辐射比值分别为 $1.3 、 1.3$ 和 1.4 , 差 异不显著。由于周年光、温变化趋势不同, 同一种 植体系两季间光、温资源分配特征也不同，然而热 量条件(积温) 是决定作物生长发育进程和产量形成 的主要因素 ${ }^{[38-39]}$, 因此积温分配可作为气候资源分 配的主要指标, 辐射分配和降水分配为次要指标。 同时, 通过调整积温分配率和分配比值的定量指标 可对周年气候资源进行季节间优化配置，为适宜熟 期品种和两季合理播种期和收获期的确定提供定量 依据。

综上所述，在明确不同种植体系周年气候资源 分配与利用特征基础上进行周年资源优化配置是提 升黄淮海地区周年产量和资源利用效率的重要途 径。本研究建立的资源分配率和分配比值等定量指 标可为两熟种植体系周年气候资源优化配置提供定 量依据, 然而作物生长季节内光温水资源的动态变 化与作物生长发育的匹配程度也影响作物产量及资

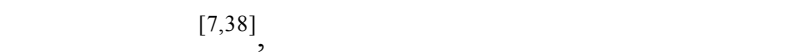




\section{段资源分配与其生长发育的定量关系对于建立更加 完善的两熟制周年资源定量优化配置方案具有重要 意义, 这也是我们下一步研究的重点。}

\section{4 结论}

在黄淮海两熟区, 冬小麦-夏玉米和双季玉米 种植体系具有较高的周年产量潜力, 同时由于充分 发挥了玉米高资源利用效率的优势, 双季玉米体系 也具有较高的周年辐射及降水生产效率、籽粒及总 生物量光能利用效率。冬小麦-夏玉米作为保障口粮 的传统种植体系, 双季玉米作为新型的资源高效种 植体系均可作为黄淮海区种植模式优化布局和农业 生产可持续发展的重要支撑。在明确主要种植体系 积温分配率和积温比值等指标基础上对周年气候资 源进行优化配置, 是进一步挖掘该区周年产量潜力 和资源利用效率的重要途径。

\section{References}

[1] 中华人民共和国农业部. 中国农业统计资料. 北京: 中国农业 出版社, 2015.

Ministry of Agriculture of the Peoples' Republic of China. China Agriculture Statistical Report. Beijing: China Agriculture Press, 2015 (in Chinese).

[2] 蔡剑, 姜东. 气候变化对中国冬小麦生产的影响. 农业环境科 学学报, 2011, 30: 1726-1733.

Cai J, Jiang D. The effect of climate change on winter wheat production in China. J Agro-Env Sci, 2011, 30: 1726-1733 (in Chinese with English abstract).

[3] 杨晓光, 刘志娟, 陈阜. 全球气候变暖对中国种植制度可能影 响: I. 气候变暖对中国种植制度北界和粮食产量可能影响的 分析. 中国农业科学, 2010, 43: 329-336.

Yang X G, Liu Z J, Chen F. The possible effects of global warming on cropping systems in China: I. The possible effects of climate warming on northern limits of cropping systems and crop yields in China. Sci Environ Sin, 2010, 43: 329-336 (in Chinese with English abstract).

[4] Borrás L, Gambín B L. Trait dissection of maize kernel weight: towards integrating hierarchical scales using a plant growth approach. Field Crops Res, 2010, 118: 1-12.

[5] Cairns J E, Sonder K, Zaidi P H, Verhulst N, Mahuku G, Babu R, Nair S K, Das B, Govaerts B, Vinayan M T, Rashid Z, Noor J J, Devi P, San Vicente F, Prasanna B M. Maize production in a changing climate: impacts, adaptation, and mitigation strategies. Adv Agron, 2012, 114: 1-58.

[6] Tao F, Yokozawa M, Xu Y L, Hayashi Y, Zhang Z. Climate changes and trends in phenology and yields of field crops in China, 1981-2000. Agric For Meteorol, 2006, 138: 82-92.

[7] Wang J, Wang E L, Yang X G, Zhang F S, Yin H. Increased yield potential of wheat-maize cropping system in the North China Plain by climate change adaptation. Climatic Change, 2012, 113: 825-840.

[8] Warrington I J, Kanemasu E T. Corn growth response to tem- perature and photoperiod: I. Seedling emergence, tassel initiation and anthesis. Agron J, 1983, 75: 749-754.

[9] Tollenaar M. Duration of the grain-filling period in maize is not affected by photoperiod and incident PPFD during the vegetative phase. Field Crops Res, 1999, 62: 15-21.

[10] Chen C Q, Lei C X, Deng A X, Qian C R, Hoogmoed W, Zhang W J. Will higher minimum temperatures increase corn production in Northeast China? An analysis of historical data over 1965-2008. Agric For Meterol, 2011, 151: 1580-1588.

[11] Liu Y E, Xie R Z, Hou P, Li S K, Zhang H B, Ming B, Long H L, Liang S M. Phenological responses of maize to changes in environment when grown at different latitudes in China. Field Crops Res, 2013, 144: 192-199.

[12] Loomis R S, Williams W A. Maximum crop productivity: an estimate. Crop Sci, 1963, 3: 67-72.

[13] 李三爱, 巨辉, 池宝亮. 作物生产潜力研究进展. 中国农业气 象, 2005, 26: 106-111.

Li S A, Ju H, Chi B L. Reviews on crop potential productivity researches. Chin J Agrometeor, 2005, 26: 106-111 (in Chinese with English abstract).

[14] 黄川荣, 刘洪. 气候变化对黄淮海平原冬小麦与夏玉米生产 潜力的影响. 中国农业气象, 2011, 32: 118-123.

Huang C R, Liu H. The effect of the climate change on potential productivity of winter wheat and summer maize in the Huang-Huai-Hai Plain. Chin J Agroneteor, 2011, 32: 118-123 (in Chinese with English abstract).

[15] 成雪峰, 张凤云. 黄淮海夏大豆生产现状及发展对策. 大豆科 学, 2010, 29: 157-160.

Cheng X F, Zhang F Y. Present conditions and countermeasures of soybean production in Huang-Huai-Hai regions. Soybean Sci, 2010, 29: 157-160 (in Chinese with English abstract).

[16] 王树安. 中国吨粮田建设. 北京: 北京农业大学出版社, 1994. Wang S A. Construction of the Grain Field with a Yield of 15 tons per Hectare in China. Beijing: Beijing Agricultural University Press, 1994 (in Chinese).

[17] 陈阜, 逢焕成. 冬小麦/春玉米/夏玉米间套作复合群体的高产 机理探讨. 中国农业大学学报, 2000, 5(5): 12-16.

Chen F, Pang H C. Research on mechanism for maximum yield of intercropping pattern wheat/corn/corn. J China Agric Univ, 2000, 5(5): 12-16 (in Chinese with English abstract).

[18] 赵秉强, 张福锁, 李增嘉, 李凤超, 劳秀荣, 史春余, 董庆裕, 张骏, 刘嘉军, 杨恩学. 黄淮海农区集约种植制度的超高产特 性研究. 中国农业科学, 2001, 34: 649-655.

Zhao B Q, Zhang F S, Li Z J, Li F C, Lao X R, Shi C Y, Dong Q Y, Zhang J, Liu J J, Yang E X. Studies on the super-high yield characteristics of three intensive multiple cropping systems in Huanghuaihai area. Sci Agric Sin, 2001, 34: 649-655 (in Chinese with English abstract).

[19] Meng Q F, Sun Q P, Chen X P, Cui Z L, Yue S C, Zhang F S, Römheld V. Alternative cropping systems for sustainable water and nitrogen use in the North China Plain. Agric Ecosyst Environ, 2012, 146: 93-102.

[20] 李立娟, 王美云, 赵明. 品种对双季玉米早春季和晚夏季的适 应性研究. 作物学报, 2011, 37: 1660-1665

Li L J, Wang M Y, Zhao M. Adaptability of varieties to dou- 
ble-cropping in early spring and late summer. Acta Agron Sin, 2011, 37: 1660-1665 (in Chinese with English abstract).

[21] 李立娟, 王美云, 薛庆林, 崔彦宏, 侯海鹏, 葛均筑, 赵明. 黄 淮海双季玉米产量性能与资源效率的研究. 作物学报, 2011, 37: 1229-1234.

Li L J, Wang M Y, Xue Q L, Cui Y H, Hou H P, Ge J Z, Zhao M. Yield performance and resource efficiency of double-cropping maize in the Yellow, Huai and Hai river valleys region. Acta Agron Sin, 2011, 37: 1229-1234 (in Chinese with English abstract).

[22] 王美云, 任天志, 赵明, 李少昆, 王晓波, 李立娟, 陈长利. 双 季青咜玉米模式物质生产及资源利用效率研究. 作物学报, 2007, 33: 1316-1323.

Wang M Y, Ren T Z, Zhao M, Li S K, Wang X B, Li L J, Chen C L. Matter production and resources use efficiency of double cropping silage maize system. Acta Agron Sin, 2007, 33: 1316-1323 (in Chinese with English abstract).

[23] 徐勇, 齐文虎, 谢高地, 章予舒. 农业自然资源利用效率的因 子-能量评价模型及其应用. 资源科学, 2002, 24(3): 86-91.

Xu Y, Qi W H, Xie G D, Zhang Y S. The factor-energy evaluation model of agricultural natural resources utilization efficiency and its application. Resour Sci, 2002, 24(3): 86-91 (in Chinese with English abstract).

[24] 周宝元, 马玮, 孙雪芳, 丁在松, 李从锋, 赵明. 冬小麦-夏玉 米高产模式周年气候资源分配与利用特征研究. 作物学报, 2019, 45: 589-600.

Zhou B Y, Ma W, Sun X F, Ding Z S, Li C F, Zhao M. Characteristics of annual climate resource distribution and utilization in high-yielding winter wheat-summer maize double cropping system. Acta Agron Sin, 2019, 45: 589-600 (in Chinese with English abstract).

[25] 杨美敏, 曾燕, 邱新法, 姜爱军. 1960-2000 年黄河流域太阳总 辐射气候变化规律研究. 应用气象学报, 2005, 16: 243-247.

Yang X M, Zeng Y, Qiu X F, Jiang A J. The climatic change of solar radiation over the yellow river basin during 1961-2000. $J$ Appl Meteorol Sci, 2005, 16: 243-247 (in Chinese).

[26] 郑海霞, 封志明, 游松财. 基于 GIS 的甘肃省农业生产潜力 研究. 地理科学进展, 2003, 22: 400-408.

Zheng H X, Feng Z M, You S C. A study on potential land productivity based on GIS technology in Gansu province. Prog Geogr, 2003, 22: 400-408 (in Chinese with English abstract).

[27] 李卫东, 张孟臣. 黄淮海夏大豆及品种参数. 北京: 中国农业 科学技术出版社, 2006. p 7.

Li W D, Zhang M C. Summer Soybean Varieties and Their Parameters at Huang-Huai-Hai Region. Beijing: Chinese Agricultural Science and Technology Press, 2006. p 7 (in Chinese).

[28] Zhang X Y, Chen S Y, Sun H Y, Wang Y M, Shao L W. Water use efficiency and associated traits in winter wheat cultivars in the
North China Plain. Agric Water Manage, 2010, 97: 1117-1125.

[29] Hu Y K, Moiwo J P, Yang Y H, Han S M, Yang Y M. Agricultural water-saving and sustainable groundwater management in Shijiazhuang irrigation district North China Plain. J Hydrol, 2010, 393: 219-232.

[30] 吴丹. 双季玉米在河北平原适应性的系统研究 . 河北农业大 学硕士学位论文, 河北保定, 2014.

Wu D. A Systematic Study on Adaptability of Maize-maize Double Cropping in the Hebei Plain. MS Thesis of Agricultural University of Hebei, Baoing, Hebei, China, 2014 (in Chinese with English abstract).

[31] Xu C L, Zhao H X, Zhang P, Wang Y Y, Huang S B, Meng Q F, Wang P. Delaying wheat seeding time and maize harvest improved water use efficiency in a warm temperature continental monsoon climate. Agron J, 2018, 110: 1420-1429.

[32] Xiong W, Matthews R, Holman I, Lin E, Xu Y L. Modelling China's potential maize production at regional scale under climate change. Clim Change, 2007, 85: 433-451.

[33] Zhou B Y, Yue Y, Sun X F, Wang X B, Wang Z M, Ma W, Zhao M. Maize grain yield and dry matter production responses to variations in weather conditions. Agron J, 2016, 108: 196-204.

[34] He L, Asseng S, Zhao G, Wu D R, Yang X Y, Zhuang W, Jin N, $\mathrm{Yu}$ Q. Impacts of recent climate warming, cultivar changes, and crop management on winter wheat phenology across the Loess Plateau of China. Agric For Meteorol, 2015, 200: 135-143.

[35] Liu Y E, Hou P, Xie R Z, Li S K, Zhang H B, Ming B, Ma D L, Liang S M. Spatial adaptabilities of spring maize to variation of climatic conditions. Crop Sci, 2013, 53: 1693-1703.

[36] Sun H Y, Zhang X Y, Chen S Y, Pei D, Liu C M. Effects of harvest and sowing time on the performance of the rotation of winter wheat-summer maize in the North China Plain. Ind Crops Prod, 2007, 25: 239-247.

[37] 周宝元, 马玮, 孙雪芳, 高卓晗, 丁在松, 李从锋, 赵明. 播/ 收期对冬小麦-夏玉米一年两熟模式周年气候资源分配与利 用特征的影响. 中国农业科学, 2019, 52: 1501-1517.

Zhou B Y, Ma W, Sun X F, Gao Z H, Ding Z S, Li C F, Zhao M. Effects of different sowing and harvest dates of winter wheat-summer maize under double cropping system on the annual climate resource distribution and utilization. Sci Agric Sin, 2019, 52: 1501-1517 (in Chinese with English abstract).

[38] Liu Y E, Xie R Z, Hou P, Li S K, Zhang H B, Ming B, Long H L, Liang S M. Phenological responses of maize to changes in environment when grown at different latitudes in China. Field Crops Res, 2013, 144: 192-199.

[39] Dong J, Liu J, Tao F, Xu X L, Wang J B. Spatio-temporal changes in annual accumulated temperature in China and the effects on cropping systems, 1980s to 2000. Climate Res, 2009, 40: 37-48. 